\title{
Canadian trials to examine "liberation procedure" for multiple sclerosis
}

Published at www.cmaj.ca on May 3

$\mathrm{D}$ uncan Thornton is still getting used to enjoying the small things that most Canadians take for granted.

"I do laundry spontaneously," says the 47-year-old resident of Winnipeg, Manitoba. Diagnosed with multiple sclerosis (MS) in August 2009, Thornton figures he's had the disease for at least two decades. "Fatigue was always the most disabling aspect of my illness. ... For the last 20 years, any time I stood for more than five minutes I began looking for a chair."

Duncan and his brother, 49-year-old Evan of Ottawa, Ontario, who also has MS, made headlines in March after travelling to a clinic in Poland for surgery nicknamed the "liberation procedure."

The operation is based on research by Paolo Zamboni, a professor of medicine at the University of Ferrara in Italy. He suspects multiple sclerosis is not, as is widely believed, an auto-immune disease, but rather a vascular condition he dubbed chronic cerebrospinal venous insufficiency, or CCSVI.

Zamboni discovered that in about $90 \%$ of people with multiple sclerosis, the veins draining blood from the brain are blocked or malformed, causing a build-up of iron in the brain. Zamboni believes that build-up causes the neurological symptoms of multiple sclerosis.

It is not a new hypothesis, according to Dr. Ian Rodger, vice-president of research at St. Joseph's Healthcare Hamilton in Ontario.

But it remains clinically untested, Rodger says. "The idea that blood vessels are involved in MS goes back over 100 years. But it rises to the surface and fades away. For the last 50 years, at least, the auto-immune theory has been somewhat dominant."

Researchers at St. Joseph's Healthcare will test Zamboni's proposition. "I

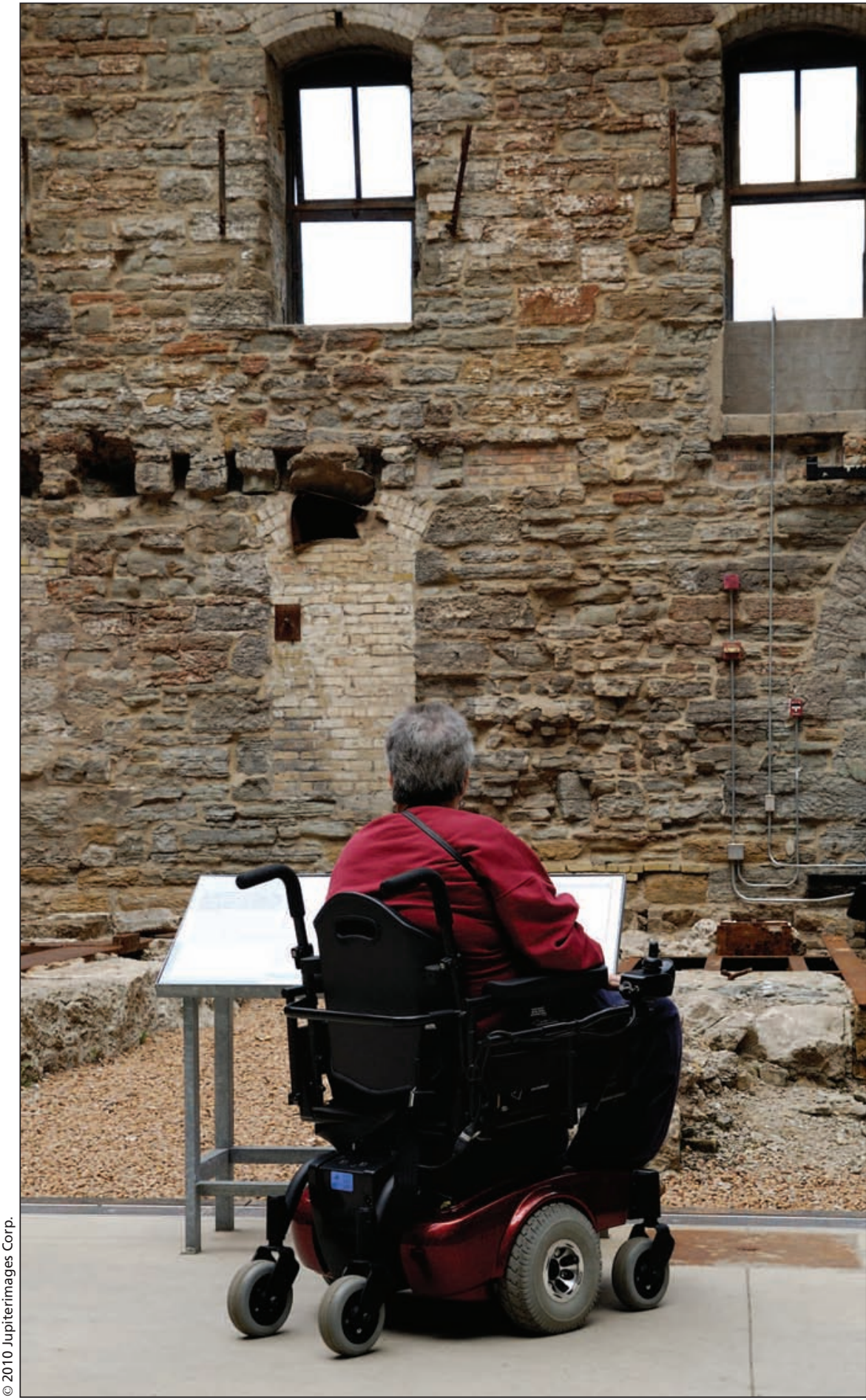

People diagnosed with multiple sclerosis are often forced to use wheelchairs because of difficulties with coordination, balance and movement. 
have no doubt that there is an autoimmune component to MS. But what Zamboni has done is he has raised the awareness again that the vascular component could be real," Rodger says. "So it could be auto-immune with a vascular component. And who knows what else? We don't know."

Rodger says his team is looking to establish the prevalence of CCSVI by comparing subjects who have multiple sclerosis with age- and gender-matched healthy people. Those 100 people will be put in four categories: primary progressive, secondary progressive, relapsing and remitting, and benign.

"Specifically, we are going to measure by ultrasound and try to mimic almost exactly, if not exactly, what Zamboni has done. We're also going to use MR [magnetic resonance] imaging to look at the architecture of the veins," Rodger says. "We're trying to see whether MR is superior to ultrasound. It's obviously a lot more expensive.
But you see different things with MR than you see with ultrasound. So really, we're going to do a comparison."

The University of British Columbia (UBC) and Vancouver Coastal Health has partnered with the University of Saskatchewan to undertake a similar research project.

"A lot of people are anxious to have a test done and surgery without having the validation done first," says Dr. Anthony Traboulsee, the medical director of UBC's MS clinic. "Our feeling is that the validation of Zamboni's original findings needs to be done first before people run off to have surgery."

"So far, that hasn't been replicated and we think that is the most important first step before going on to treatment trials," Traboulsee adds.

The UBC-led team will compare the use of catheter venography with ultrasound and magnetic resonance venography as methods of validating the presence or absence of venous abnor- malities in people with multiple sclerosis, compared with those without.

"We're also looking to see if it's real," Traboulsee says. "That's what the whole community is waiting for. Is this real or is this fantasy? If results have only come out of one group, then that is interesting but not proof in itself. So a completely independent research group needs to reproduce what somebody else did to prove it's a valid abnormality."

"The first step is to reproduce Zamboni's findings," he adds. "The second step is to find what test is good enough to find the abnormality, so we're doing both of those in one study. Then the third step would be to show if treatment is beneficial. Unless we do the proper studies, a lot of people are going to be exposed to surgery for this potential abnormality and may get a risk from the surgery without getting a clear sustainable benefit." Becky Rynor, Ottawa, Ont.

DOI:10.1503/cmaj.109-3251 